\title{
El plan de transición y plebiscito para sustituir al régimen de Franco. El inicio de la Guerra Fría (1945-1951)
}

\author{
Miguel Ángel Yuste de Paz
}

Poco tiempo después de terminada la II guerra mundial, las esperanzas del exilio republicano español en que la derrota del Eje traería la caída automática de Franco se desvanecen y empieza a calar la idea de que era necesario propiciar la unidad de las fuerzas opositoras al franquismo, incluso de las no republicanas, que pudiera dar lugar a una alternativa con posibilidades de ser apoyada por las potencias democráticas, con el fin de plantear una consulta al pueblo español sobre la forma de régimen politico que deseaba, una vez expulsado Franco del poder. A la confianza de los republicanos partidarios del plebiscito en ganar se unirá el convencimiento de que era necesario pasar por esa prueba de ratificación que les investiría de una nueva legitimidad.

Como dice Julio Aróstegui en su estudio sobre la oposición en el exterior de España, fue Francisco Largo Caballero el que mejor definió la estrategia llamada de transición y plebiscito, aunque Indalecio Prieto seria el precedente, y también el heredero de su formulación ${ }^{1}$. La propuesta de Largo consistía en conseguir que la ONU impusiera a Franco un plan por el que se entregaría el poder a un gobierno de funcionarios y magistrados no relacionados con la represión, que tras una serie de medidas esenciales para el logro de un clima de libertad, como la expatriación de Franco y de los responsables más importantes de la represión, cederia el poder a un gobierno con representación de todos los interesados en celebrar un plebiscito sobre la forma de régimen político, fuese éste republicano o monárquico.

Julio Aróstegui, Nuevas aportaciones al estudio de la oposición exterior: Largo Caballero y la politica de "Transición y Plebiscito", en El primer franquismo, España durante la segunda guerra mundial, Edición al cuidado de J. L. Gafcia DELGADO, siglo xxı, Madrid, 1989, pág. 317. 
La trayectoria política de Prieto en estos años se caracterizará por su anticomunismo, su enemistad con Juan Negrín, y su enfrentamiento más o menos directo con los distintos gobiernos republicanos en el exilio, debido al cuestionamiento no ya sólo de la legitimidad del gobierno, sino de su propia existencia, postura ésta compartida por Largo Caballero, que a finales de 1945 afirmaba que:

el gobierno de Giral no admite otra fórmula que la que Franco le entregue directamente el poder. Si se obstina en esa absurda actitud y nosotros no nos decidimos a emprender otros caminos, con su visto bueno, o si él, Franco se eternizará en el poder y los españoles exiliados quedaremos reducidos a una especie de Judea esparcida por el mundo. Sin que tenga él la culpa, el gobierno es hoy el mayor obstáculo para encontrar una fórmula honrosa de solucionar tan grave problema? ${ }^{2}$.

Indalecio Prieto pugnará por conseguir una posición dominante dentro del socialismo español, profundamente dividido ya desde la guerra civil. En el fortalecimiento de su posición, sin duda influirá su estrecha relación con Largo Caballero en el período anterior a la muerte de éste en marzo de 1947. Prieto se volcará en la creación y en la consolidación de distintas organizaciones políticas, basándose en las recomendaciones de la ONU y de la Nota Tripartita para resolver el problema español. Su participación en la Junta de Asistencia a los Republicanos Españoles (JARE), la Junta Española de Liberación (JEL), o la Alianza Nacional de Fuerzas Democráticas (ANFD), serán ejemplo de ese empeño, pese a que su voluntad integradora dejará al margen a los comunistas, incompatibles, según Prieto, con cualquier proyecto que pudiera recoger el apoyo de las potencias occidentales.

Muchos dirigentes del exilio, entre ellos Prieto, tenían sus esperanzas depositadas en la ayuda británica, y más tras la victoria electoral del partido laborista en 1945. El entonces primer ministro Attlee, había asegurado poco antes de ganar las elecciones que se volcaría en apoyar a los republicanos cuando alcanzara el poder. Sin embargo, los republicanos se enfrentarán a un momento histórico en el que además del posibilismo de su politica exterior, el Reino Unido ha pasado a ser una potencia de segundo orden en la posguerra mundial, pese al gran prestigio conservado por su diplomacia. El nuevo período histórico, que se caracterizará por la in-

2 Citado por José Borfas en Políticas de los exiliados españoles, 1944-1950. Ruedo lbérico, Chatillon-sous-Bagneux, 1976, pág. 114. Francisco Largo Caballero, Mis recuerdos, págs. 354 , 377 y 278 , Edi. Alianza, México, 1954. 
fluencia creciente de la política exterior de los Estados Unidos, coincidente en un principio con la inglesa respecto a España, introducirá al problema españoi en una nueva e interesada política de bloques, en la cual se difuminará al dictado de las prioridades del momento. No obstante, el Reino Unido jugó un importante papel en la búsqueda de un acuerdo entre la oposición republicana y monárquica al franquismo, auspiciando las conversaciones que mantendrán Prieto y el representante de los monárquicos, José María Gil Robles, en octubre de 1947. El pacto con los monárquicos encajaba con el plan de transición ya mencionado para la celebración de un plebiscito, aunque en las primeras formulaciones de Largo Caballero no se hablara de pacto sino de participación de todas las fuerzas opositoras.

Si bien ya en julio de 1942, Prieto se había pronunciado en La Habana sobre la necesidad de un plebiscito, es en el artículo O Plebiscito o Monarquía ${ }^{3}$ publicado el 8 de marzo de 1947, donde manifestó con una mayor claridad sus críticas a los que querían volver a la situación jurídica de 1936, como si nada hubiese sucedido, y también sus propuestas, respecto al futuro. Cuanto iriamos a perder lo tenemos perdido de antemano. Colocados en el punto de vista de los intransigentes más tenaces, perderíamos, a lo sumo, una legitimidad, perfecta desde puntos de vista juridicos, pero inefectiva. Partía del supuesto de que las presiones internacionales se incrementasen, lo que provocaría la caída de Franco, que al verse perdido reaccionaria cediendo el paso a la monarquía, ya que ésta podría salvarle, cosa que no haría la República. Era necesario pues, adelantarse a esa solución provocando un plebiscito. El plebiscito no nos puede situar en planos inferiores al deplorable que ahora ocupamos, ni a ese otro - la monarquía- en perspectiva, tampoco satisfactorio. Por consiguiente, cerrar el único camino practicable con romanticismos e intransigencias constituye una gran torpeza. Una monarquía implantada por decisión de Franco o de otros jerarcas militares contendría en germen el despotismo. Por el contrario, si fuese resultado de un plebiscito, apareceria limpia de un tóxico tan pernicioso. Para llevar a cabo el plebiscito Prieto contemplaba dos formas, una estrictamente plebiscitaria por la que el pueblo diria directamente el régimen político que prefería, y otra de carácter constituyente, en la que de manera indirecta, lo diria a través de candidatos elegidos. El periodo constituyente ha de serlo tan completo que los bandos enfrentados deberán considerar que nada subsiste de lo anterior. La idea era que sólo renunciando a los principios legitimistas que monár-

IndAlecio Prieto, O Plebiscito o Monarquia, "L'Espagne Republicaine", 8-3-1947. 
quicos y republicanos aducían para sustituir a Franco, sería posible construir la democracia en España, la cual debería nacer de la decisión de los españoles al votar la forma de gobierno. Prieto añadía que el panorama debemos contemplarlo más que como republicanos como españoles.

\section{POR LA RUPTURA DEL INMOVILISMO REPUBLICANO}

Que duda cabe de que la existencia del gobierno republicano era un valioso referente para los miles de españoles que se habian visto obligados a salir de España, y también para la oposición antifranquista del interior, pero al mismo tiempo, fue un símbolo que recordaba al mundo la existencia de una dictadura en España. Sin embargo, su influencia en la escena política española e internacional, y por supuesto en el exilio, fue casi nula, sobre todo a partir de 1950.

La segunda guerra mundial había representado para las instituciones republicanas del exilio el olvido internacional y una nueva dispersión geográfica de sus miembros, por lo que el triunfo aliado concitó todas las esperanzas de los españoles desterrados, ahora que el fascismo había sido derrotado en Europa. Pero el dictador, que habia jugado un papel acomodaticio a las circunstancias del desarrollo de la guerra, aspiraba también a ocupar un puesto en la sociedad internacional si el enemigo comunista se convertía, como vaticinaba, en el principal problema de los vencedores en tiempos de paz. Para muchos dirigentes republicanos estaba claro que los nuevos tiempos que se avecinaban requerian un cambio de estrategia y una organización con instituciones realmente representativas que trabajaran por lograr el apoyo de la sociedad internacional a las justas reivindicaciones de la otra España.

Prieto entendió muy pronto que los paises democráticos no apoyarian a un gobierno débil del que además formasen parte los comunistas, por ello apoyó la alianza de partidos que se conoció como JEL (Junta Española de Liberación), de la que fue secretario, con el fin de conseguir un organismo de amplio respaldo que superase el anquilosamiento que mermaba a las instituciones del exilio, y hacer frente al mismo tiempo a las pretensiones hegemonistas de la Unión Nacional Española fundada en noviembre de 1942, a iniciativa del Partido Comunista, que aspiraba a instaurar en España un gobierno de Unión Nacional representativo de todas las fuerzas políticas no infeudadas en el extranjero. Es importante recordar que la temprana estancia de Prieto en México, donde dominó la administración de la JARE, (Junta de Asistencia a los Republicanos Españoles), en perjuicio de la gemela SERE, (Servicio de Evacuación de los Republicanos 
Españoles) dominada por Negrín, le había proporcionado una gran influencia en el mundo del exilio.

El pacto de unidad que dio a la luz la JEL fue aprobado por dirigentes del PSOE, Izquierda Republicana, Unión Republicana, Esquerra Republicana de Catalunya, y Acción Catalana el 20 de noviembre de 1943. La JEL desplegó una gran actividad, aunque con altibajos, hasta septiembre de 1947, destacando su labor en la Conferencia de San Francisco en junio de 1945, en la que, y por la mediación del representante mexicano, se consiguió la exclusión de España de las nacientes Naciones Unidas. La exclusión sería ratificada por la declaración de Postdarn en julio, debido a la íntima relación de España con los estados del Eje.

Cuando en agosto de 1945 se reorganizaron las instituciones republicanas del exilio, y se proclamó al hasta entonces Presidente interino Diego Martinez Barrio, Presidente de la República, éste encargó la formación de gobierno a José Giral, tras rechazar al anterior presidente Juan Negrín, que había perdido el apoyo mayoritario de su partido y de una gran parte de los representantes de los otros partidos. En el memorándum del acto de constitución del nuevo gobierno, éste manifiesta que su propósito fundamental es la restauración de la Constitución de 1931, en cuanto última declaración hecha por el pueblo español de su voluntad de establecer un régimen liberal, democrático y parlamentario ${ }^{4}$. En la votación de confianza, Prieto contestará que apoyarán a las nuevas instituciones hasta donde el éxito acompañe a la acción de gobierno 5 , lo que suponía un aviso y un desafío por parte del dirigente socialista. Otros dirigentes, como Negrin, Trifón Gómez, o Luis Araquistain, manifestarían con el tiempo su desacuerdo con Giral, pues aun deseando la restauración republicana, se dieron cuenta de las dificultades casi insalvables de que ésta se produjese sin una transición previa. Incluso Dolores Ibarruri se dirigió por carta a Giral en diciembre de 1945:

El Partido Comunista, en su deseo de poner fin a los sufrimientos de nuestro pueblo y evitar nuevas luchas sangrientas que consumen la ruina de nuestro pais, está dispuesto a ltegar a un acuerdo con todas las fuerzas antifranquistas nacionales sobre la base de la organización de una consulta a| pueblo, en la que éste, libre y democráticamente, se pronuncie por el régimen en que quiere vivir y gobernarse ${ }^{6}$.

4 ARE, 1.3.2, 675.6., Memorándum de las Cortes de México, 17-8-1945, FUE

5 Citado por JOSE M. ${ }^{a}$ DEL VALLE en Las instituciones de la República española en exilio, Ruedo Ibérico, Paris, 1976, págs. 134 y 135. Extracto oficial de la sesión extraordinaria del Congreso de los Diputados en Ciudad de México, 7-11-1945.

' ARE, 1.3.2, 655.2., Carta de D. Ibarruri a José Giral, 19-12-1945, FUE. 
Este clima de contestación irá debilitando poco a poco la posición del gobierno, y provocará una asunción paulatina del protagonismo representativo de los gobiernos del exilio por parte de organizaciones como la Alianza Nacional de Fuerzas Democráticas, (ANFD), y de dirigentes políticos como Indalecio Prieto. La ANFD se había creado a finales de 1943 con la participación de republicanos, socialistas y cenetistas, y reclamaba el restablecimiento del orden republicano, aunque también la creación de un gobierno democrático que asumiera todos los poderes en tanto no se consultara la voluntad popular, apoyado en los partidos y organizaciones en el representados ${ }^{7}$. La ANFD mantuvo numerosos contactos con militares monárquicos como los generales Aranda y Kindelán, con el fin de construir una amplia coalición que diese paso a un gobierno provisional compuesto por miembros de la ANFD y militares monárquicos tras la caída de Franco, lo que le distanciaría poco a poco del gobierno.

Mientras tanto, el 26 de febrero de 1946 el gobierno francés decidió cerrar sus fronteras con España a partir del día 1 del mes siguiente, con la intención de que Franco rompiera sus relaciones con Francia, pero Franco se adelantó cerrando la frontera un día antes de lo anunciado por Francia. Pese a las Ilamadas de Francia a Gran Bretaña y Estados Unidos con el fin de adoptar una política enérgica respecto a Franco, sólo consiguió, a sugerencia de Estados Unidos, una declaración de los tres paises conocida como Nota Tripartita, que se publicó el 5 de marzo:

No entra en nuestras intenciones intervenir en los asuntos interiores de España. El pueblo español debe, a fin de cuentas, fijar su propio destino. Deseamos que unos dirigentes españoles patriotas y liberales consigan provocar la retirada de Franco, la abolición de la Falange, y el establecimiento de un gobierno provisional [...], bajo cuya autoridad el pueblo español tuviera la posibilidad de determinar libremente el tipo de gobierno que desea y elegir a sus representantes ${ }^{8}$.

La declaración no fue recibida con excesivo entusiasmo por el gobierno, que esperaba la ruptura económica y diplomatica de las tres potencias con Franco ${ }^{9}$, pues se limitaba a condenar a su régimen, pero rechazaba la intervención directa para acabar con él, y además, no hacía mención al gobierno republicano. Esto último suponia una prueba del escaso crédito que las potencias democráticas daban al gobierno republicano, lo que confirmaba el punto de vista de Prieto y Largo Caballero al respecto. A Prieto

Citado por José M. a DeL VAlLE, op. cit, págs. 136 a 139. Comunicado de la ANFD.

ARE, 1.13.2, 735.1., Declaración Tripartita, 5-3-1946, FUE.

ARE, 1.5.2, 37.1., Carta de José Giral a Juan A. Meana, 8-3-1946. FUE. 
no le gustaba el cariz que estaba tomando el problema español en el ámbito internacional, y asi se lo manifiesta en una carta con fecha 18 de junio de 1946 a su amigo Toribio Echeveria:

Habiendo agotado todos los supuestos para explicarme la actitud de las Democracias para con nosotros, es cada vez mayor mi confusión y desconcierto. Sólo me resta temer que nuestra atomización política, pese a las apologias unitarias que usamos, haga creer a Inglaterra y América, que una vez libres y dueños de nuestro destino, seriamos presa fácil de la demagogia comunista al apoyo de sus valimientos de Moscú, para recaer en una mediatización y una esclavitud politica tan dura como la anterior, y esto les aconseja a tuertas o a derechas el desconocer nuestro derecho y descuidar sus obligaciones ${ }^{10}$.

En 1946, El Reino Unido justificaba el mantenimiento de sus relaciones con España porque por un lado le permitía tener información de primera mano sobre los acontecimientos internos del país, y por el otro, porque creía que la ruptura reforzaría la posición de Franco, como sucedió con el cierre de fronteras por parte de Francia, y con la discusión del problema español en el Consejo de Seguridad de la ONU. No obstante, existian motivos mas interesados: la interrupción de relaciones comerciales perjudicaría seriamente al abastecimiento de productos alimenticios en el Reino Unido, encarecería su producción de hierro, perjudicaría el consumo interno de bienes, y finalmente, pondría en graves aprietos a sus mercados financieros. Por otro lado, Gran Bretaña no confiaba en el gobierno Giral, no le consideraba capaz de acabar con Franco, ni tampoco que representara realmente a los españoles de dentro y de fuera. Asi que, junto a su oposición a la ruptura de relaciones, los británicos se negaban a reconocer al gobierno del exilio, y se mostraban partidarios de una política de presión por medio de canales diplomáticos que pudiera crear un clima de tolerancia política dentro de España que reforzara a la oposición democrática. El representante británico en la ONU, Alexander Cadogan, había hecho saber al Consejo de Seguridad en junio, que el problema español era esencialmente un problema de jurisdicción interna, y que cualquier intervención violaría la carta de la ONU, pues representaría un precedente grave que permitiria interferencias futuras en otros paises ${ }^{11}$.

A finales de marzo se había producido la incorporación al gobierno Giral del comunista Santiago Carrillo, del galleguista Rodriguez Castelao,

\footnotetext{
10 Citado por Pablo Hormigos en Cartas de la España peregrina: la correspondencia entre 1 Prieto y Toribio Echeverria, Cuadernos Republicanos, $n^{\circ}$ 25, Madrid, CIERE, enero 1996, pág 111. En T. Echeverfia - I. Prieto, Epistolario 1941-1946, Itxaropena-Ego lbarra, 1991, pág. 88.

11 FO 371-60364, Z 8056, Minuta F.O., 14-9-1946, PRO.
} 
y del miembro de la derecha republicana Sánchez Guerra, con el fin de ofrecer una imagen de mayor representatividad de las fuerzas políticas existentes, pese al riesgo de que la inclusión de un comunista en el gobierno no gustara a los ingleses ni a los norteamericanos. El congreso celebrado por el PSOE en Toulouse entre el 22 y el 26 de mayo, renovó, no obstante, el apoyo socialista al gobierno tras su reestructuración, pero también dejó claro que el partido no se opondría a ninguna fórmula que fuese propuesta y que pudiera tener éxito, por vias diferentes de las que estaban indicadas en la Constitución. Respecto a la inclusión de un comunista en el gobierno, declaraba que era responsabilidad exclusiva del jefe de gobierno, y que sólo por razones de peso, determinadas por las circunstancias, aceptaba una situación que no implicaba acuerdo o compromiso político por parte del partido. También hacia un llamamiento a todos los partidos socialistas del mundo para que presionasen a sus gobiernos para lograr la ruptura de relaciones diplomáticas y comerciales con España, adelanto de lo que Prieto esperaba de la reunión de la Asamblea general de la ONU que comenzaría el 23 de octubre de 1946.

Pero la resolución que las Naciones Unidas aprueban el 15 de diciembre de 1946 no colmó las expectativas despertadas, a pesar de la importancia de su contenido. La resolución fue el resultado de los trabajos británicos y estadounidenses por evitar que se aprobara la proposición del delegado polaco Oscar Lange, que abogaba por la ruptura de relaciones diplomáticas y económicas. Estados Unidos sólo estaba dispuesto a tomar medidas contra Franco si se probaba que su régimen era una amenaza para la paz mundial. Finalmente, la resolución fue aprobada incluyendo la condena del régimen y la recomendación de impedir a España la participación en los organismos internacionales, además de la retirada de los embajadores acreditados en Madrid, y reservándose para el futuro, sin ningún plazo prefijado, nuevas medidas si no se establecía un gobierno representativo en España. La resolución no contenía tampoco mención alguna al gobierno del exilio ni a la legalidad republicana, y tampoco ningún compromiso firme para acabar con Franco.

A su regreso de Nueva York, Giral se muestra esperanzado y contento por los resultados, aunque no hayan sido del todo satisfactorios para sus aspiraciones, y se apresta a llevar al Consejo de Ministros nuevos proyectos para reforzar las actividades opositoras de las instituciones republicanas, pero comprueba que sus planes no son compartidos, y que además, su gobierno se desmorona, lo que conducirá a su dimisión y a la constitución de un nuevo gobierno presidido por el socialista Rodolfo Llopis en febrero de 1947. Pero, para una gran parte del PSOE y de la ANFD el cambio de gobierno no era suficiente, la resolución de la ONU tendría que haber provo- 
cado la disolución del gobierno en el exilio y su sustitución por un organismo representativo de todas las fuerzas antifranquistas. Pese a todo, el nuevo presidente era del PSOE, partido que junto a la UGT había propiciado la dimisión de los miembros socialistas del gobierno anterior, e influido en la misma dirección a los ministros de la CNT. Martínez Barrio parecía estar de acuerdo con los socialistas en propugnar el acercamiento a todas las fuerzas antifranquistas posibles, sin menoscabar la legalidad republicana, para lograr lo más importante, derribar a Franco, luego el pueblo decidiría. Al hilo de estos planteamientos, Llopis dejó la puerta abierta a que en el futuro, el gobierno se abra a otras representaciones, cuando en el curso de nuestra actuación, las circunstancias asi lo aconsejen. Además, el gobierno se consagrará a impedir que pueda establecerse en España ningun régimen, de no ser el republicano, sin que previamente se haya manifestado la voluntad de los españoles al respecto. También manifestó la voluntad de que la actuación del gobierno esté dentro de la órbita de la ONU ${ }^{12}$.

La ANFD miró esperanzada entonces los primeros pasos del nuevo gobierno, también Prieto. Pensaron que Llopis iba a ser el encargado de disolver la institución y sustituirla por una Junta, que terminará con la legalidad republicana ${ }^{13}$, pero no fue asi. Pronto quedaron de manifiesto los escasos avances registrados en el proyectado trabajo en común con otras fuerzas de oposición, y también el escaso apoyo internacional con que contaba. En el curso de una entrevista celebrada en julio de 1947 entre un miembro de la oposición del interior de España y el encargado de negocios americano en Madrid, Culberston, este le dice:

¿Cómo vamos a reconocer al gobierno republicano sin saber cual es la auténtica voluntad del pueblo español?, y aunque le reconociésemos, ¿qué fuerza tiene para entrar a gobernar a España? ¿Tendriamos que intervenir militarmente para imponerlo? Se trata de un imposible. La única solución es un gobierno de coalición y concentración, tolerado y acatado por el Ejército, ligeramente depurado, que conceda al pueblo las libertades de la Carta del Atlántico y convoque unas elecciones libres de tipo constituyente. El gobierno que salga de ellas si que tendrá todo nuestro apoyo económico, moral y, si lo precisa, nuestro refrendo armado como el griego ${ }^{14}$.

En este periodo tambièn se registra la propuesta realizada por un colaborador de Llopis, Rafael Valero, a Don Juan, en la que le hace ver la bondad de fir-

ARE, 1.3.2, 23.5., Declaración del Gobierno Llopis, 14-2-1947, FUE.

13 Foreign Office (FO), FO 371-67872, Z 1768, Carta embajada en Madrid a Bevin, 14-21947. Public Record Office (PRO), Londres.

is ARE, 1.3.2, 803.2., Entrevista Vivar-Culberston, 12-7-1947, FUE. 
mar un manifiesto común entre el Pretendiente y el Presidente de la República, es rechazada con la excusa de que si accediera, perdería la adhesión de la mayor parte de los monárquicos españoles, haciéndole el juego a Franco ${ }^{15}$.

Para el Foreign Office, los generales españoles rechazarían cualquier alternativa a Franco que trajera la República, aunque fuese ampliamente respaldada internacionalmente, pero es que además, el gobiemo de Llopis carecía de esos apoyos, por tanto, sólo parecía viable una alternativa alrededor de $\mathrm{D}$. Juan. El departamento británico creía que había que convencer a los americanos, dejando al margen a los franceses, de que sólo un gobierno bajo la influencia de D. Juan podia ser apoyado por los dos paises, ya que los generales no aceptarian un plebiscito si no estaban seguros de que D. Juan ocuparía el trono, y tampoco el pretendiente estaria de acuerdo con consultar previamente al pueblo. Además, la monarquía así iniciada estaría viciada de antemano, pues una monarquía constitucional no puede ser traída por una votación, ya que debe estar por encima de la arena política, porque si el resultado es adverso para la izquierda, ésta podría reclamar constantemente nuevas consultas.

El método propuesto será la asunción inmediata del poder por D. Juan una vez se hubiese marchado Franco, y con el gobierno fuera de España, un voto afirmativo para el gobiemo significaría entonces la aceptación de la monarquía, sin comprometer su posición si el voto no fuese masivamente a favor del gobierno. El plan no dejaba de tener inconvenientes para los angloamericanos, en primer lugar, suponia el abandono de la politica de no injerencia, en segundo lugar, que se acusara a D. Juan de haber sido impuesto por ellos, y por último, las serias dificultades que encontraria el plan en sus propios paises por razones de política interna ${ }^{16}$. Pero, para el Foreign Office sólo existian dos alternativas: la intervención en los asuntos internos españoles sin certeza de alcanzar el resultado que nosotros queremos, o sea, un cambio que asegure sus intereses, sin riesgos de radicalización, hacia la democracia occidental, o la no intervención, con igual incertidumbre de alcanzar un resultado inmediato, bueno o malo. Si la retirada de embajadores, o las sanciones económicas, perjudicaban los intereses angloamericanos mientras beneficiaban a la URSS, y la España de Franco no era una amenaza para la paz mundial, al final la no intervención se presentaba como la alternativa más segura, para lo que había que acordar una política común con los Estados Unidos ${ }^{17}$.

\footnotetext{
ARE, 1.12.4, 23.3., Carta de Rafael Valero a Rodolfo Llopis, 3-4-1947, FUE. FO 371-67868, Z 4613/3/41, Minuta F.O., 19-5-1947, PRO.

FO $371-67868, Z$ 4 4093, Embajada en Moscú a Londres, 27-4-1947, PRO.
} 
En una carta a "The Observer" el 20 de abril de 1947, a raíz de una entrevista realizada por este diario a D. Juan, Salvador de Madariaga desmontaba los argumentos para la no intervención extranjera en España.

De propósito o no, la Gran Bretaña y Estados Unidos han estado interviniendo durante largo tiempo para mantener a Franco en el poder. Por ejemplo, al no echarle cuando cayó Hitler, o al firmar el reciente acuerdo comercial. El argumento usual para no intervenir era que no habria una alternativa capaz de hacerse cargo de España si franco caía. Ahora tenemos una declaración que obliga públicamente al pretendiente a respetar los principios constitucionales y liberales que Occidente pudiera requerir; además, la solución monárquica liquidaria la guerra civil, ya que no representa a los vencedores ni a los vencidos en ella. En consecuencia, parece estar libre el camino para derrocar un régimen totalitario que priva a Occidente la autoridad moral para hablar de la libertad y la democracia. ¿Cómo?, cuando hay voluntad hay siempre un camino ${ }^{18}$.

El 25 de julio tuvo lugar en Toulouse una asamblea de delegados del PSOE en la que Llopis explicó lo realizado por su gobierno. Prieto, que había llegado a Francia el día 21 dispuesto a dar batalla, se sentía acuciado por las noticias que le llegaban de España en las que se hablaba del peligro de una instauración monárquica por cesión de Franco o por imposición de algunos generales, que tenía visos de convertirse en realidad lo que dejaría al PSOE, y a toda la oposición republicana, sin cartas por jugar y a merced de las decisiones del nuevo régimen. Prieto vio aprobada su propuesta en la que insistía en que el PSOE en el exilio no se opondría a ninguna fórmula que, por caminos diferentes de los que la Constitución trace al gobierno, pudiera conducir a la liberación de España y a la restauración de la República sin efusión de sangre, y decidió emprender una acción para que todas las organizaciones antifranquistas aceptasen la fórmula de las Naciones Unidas, para lograr un acuerdo que permitiese crear un instrumento de gobierno que representase verdaderamente al pueblo español, que fuese reconocido por la Asamblea de las Naciones Unidas en su reunión de septiembre de 1947. La propuesta declaraba al PSOE incompatible con el gobierno republicano si éste se oponía a las resoluciones aprobadas por el partido, y sólo si el gobierno daba un valor simbólico al mantenimiento de las instituciones republicanas. También se mostraba contrario a la participación de los comunistas en cualquier gobierno provisional.

La fortaleza de la posición de Prieto es ratificada por el apoyo de la mayoría de su partido, a la que se suma la creciente simpatía que despierta

is ARE, 1.12.4., 24.3., Carta de $S$. de Madariaga, 20-4-1947, FUE. 
en otros sectores del exilio, lo que le permite prescindir de cualquier compromiso con un gobierno cada vez más mermado en su peso político. Como consecuencia, el ejecutivo quedaba visto para sentencia, y el 6 de agosto Llopis presenta su dimisión. La ANFD comunicó el 15 de octubre su apoyo al plan Prieto. A mediados de noviembre, sin embargo, serán detenidos casi todos sus dirigentes, con lo que la ANFD quedó prácticamente desarticulada.

El nuevo gobierno lo formará Álvaro de Albornoz el 27 de agosto, y estará compuesto por ministros de partidos republicanos exclusivamente.

\section{LAS NEGOCIACIONES CON LOS MONÁRQUICOS Y LA DECLARA- CIÓN DE SAN JUAN DE LUZ}

El 26 de septiembre de 1947 se entrevistan en Londres Indalecio Prieto y el ministro de exteriores britanico, Ernest Bevin. En dicha entrevista Prieto le propone la publicación de una nueva Nota Tripartita semejante a la de 1946 pero mas específica, que dejara claro que las tres potencias no reconocerian la restauración de una monarquía excepto si lo deseaba el pueblo. Además, las tres potencias proclamarían su deseo de ver una coalición monárquico-socialista instalada en España. Prieto creía que dicha Declaración evitaría que el problema español pasara por la Asamblea de las Naciones Unidas, ya que pensaba que sólo era una plataforma de debate, y que los destinos de España estaban realmente en las manos de Londres, Washington y, en menor grado, de Paris ${ }^{19}$.

Gracias al apoyo de Bevin, y al importante papel del socialista Luis Araquistain, que incluso pidió al ministro inglés su apoyo a la postura del PSOE en las negociaciones ${ }^{20}$, Prieto y Gil Robles se entrevistaron en Londres en cuatro ocasiones los días 15, 17 y 18 de octubre, logrando un alto grado de acuerdo en la mayoría de los siete puntos que se debatieron para llegar a un pacto ${ }^{21}$. El resultado de los encuentros, sin embargo, no satisfizo a ninguno de los dos negociadores. El obligado secretismo, y la falta de concreción a la hora de plantear la forma de llevar a la práctica el posible acuerdo, ya que no estaba sólo en sus manos, sin duda influyó en

\footnotetext{
19 FO 371-67873, Z 8562/16/41, Conversación Prieto-Bevin, 29-9-1947, PRO.

2 Javier Tusell, Estudio preliminar sobre Luis Araquistain, pág. 89, en Luis ARAquistain, Sobre la guerra civil y en la inmigración, Espasa-Calpe, Madrid, 1983.

21 FO 371-67908 A, Z 9381 y Z 9382, Memorandums de Prieto y Gil Robles para el gobiemo británico, 19/18-10-1947, PRO.
} 
ello. Hay que tener en cuenta que los monárquicos no eran un grupo unido y homogéneo, y Gil Robles no representaba a todas las tendencias existentes dentro de su bando, donde el verdadero líder era D. Juan de Borbón. cuyas ambigüas manifestaciones no ayudaban precisamente al entendimiento de las partes, todo lo cual situaba a Gil Robles en una posición incómoda que disminuía su capacidad de negociación, y que aumentaba la desconfianza de los republicanos hacia la sinceridad de los monárquicos en las conversaciones. En ef lado contrario, y aunque no recogiese tampoco toda la unanimidad en su persona, Prieto habia sabido maniobrar para convertirse en el líder más importante de la alternativa republicana, y contaba con casi el total apoyo de su partido, de UGT y CNT, y de varios dirigentes de partidos republicanos.

Las conversaciones continuaron entre los dos líderes epistolarmente y por medio de representantes autorizados. En enero de 1948 el socialista Fernando de los Ríos recibió indicaciones de Félix Vejarano para reanudar las conversaciones, ofreciéndole una nueva propuesta de parte de Gil Robles ${ }^{22}$. En ésta se señalaba la necesidad de llegar a una fórmula conservadora debido a la negativa repercusión que las conversaciones de octubre en Londres habian tenido en España, y al peligro añadido de que la oposición de Estados Unidos y Gran Bretaña a soluciones susceptibles de producir el caos, les inclinase a la aceptación de Franco como mal menor. También se recordaba la oposición del Vaticano a cualquier solución que alarmara a los católicos. Pero a Prieto no le gustó el contenido, que proponía la formación de un gobierno-regencia que convocaría una consulta sobre un texto orgánico, y sólo se mostró dispuesto a estudiar la convocatoria para la elección de un organismo constituyente. Sin embargo, en mayo de 1948 el acuerdo parecia cercano. Prieto luchaba por evitar la ruptura de las conversaciones por sus consecuencias catastróficas, y porqué no contaban con mucho tiempo.

El principal objeto de nuestra negociación, desde el punto de vista internacional, es privar a las potencias de cualquier pretexto para lavarse las manos, que les haga desentenderse del problema español, y que confirme la creencia del fanatismo del pueblo español, por la intransigencia de ambas partes, y nuestra incapacidad de lograr una fórmula de solución para nuestro problema, que en último caso, siempre nos concierne a nosotros ${ }^{23}$.

22 FO $371-73358, \mathrm{Z}$ 1027, Memorándum de 1. Prieto sobre correspondencia con $F$. de los Ríos para Bevin, 5/12-1-1948, PRO.

2.3 FO 371-73358, Z 5113, Memorándum de Gil Robles sobre correspondencia con Prieto. para Bevin, 25-5-1948, PRO. 
El dirigente socialista era consciente de que los Estados Unidos habia iniciado un giro fundamental en su política hacia España que podía tener consecuencias indeseadas. $Y$ no se equivocaba, el 24 de octubre de 1947, al mismo tiempo que Prieto y Gil Robles iniciaban sus conversaciones en Londres, el Secretario de Estado norteamericano Marshall, aprobaba un informe de su departamento, de capital importancia para el futuro de España, en el que se recogen entre otras cuestiones, que hay serias dudas respecto a eliminar al régimen de Franco por medio de los esfuerzos del Departamento con medidas de presión internacionales. Ha llegado el momento, de que para el bien de nuestros intereses nacionales, modifiquemos nuestra política hacia España con vistas a una pronta normalización de nuestras relaciones mutuas, politicas y económicas, lo que también supone una modificación en las instrucciones bajo las que está operando nuestra delegación ante las Naciones Unidas ${ }^{24}$. Estaba claro que España no iba a ser ajena a la nueva política norteamericana de influencia en el mundo, que a la par que hacer frente al comunismo, trataba de conseguir nuevos mercados para su influyente y poderosa economía.

Los ingleses no creían en que Franco fuese el único hombre que pudiera salvar a España del comunismo. También pensaban que la ayuda económica a su régimen malograba la credibilidad democrática de los americanos, y como consecuencia la colaboración europea en la democratización de España ${ }^{25}$. Pero Estados Unidos no consideraba correcta la apreciación inglesa, ni tampoco la sugerencia de que una apelación a Franco para que abandonase el poder fuese a tener éxito. La constancia de que la oposición estaba desunida les lleva a deducir que los únicos que se beneficiarian a largo plazo por la situación de inseguridad que ello creaba, serian el partido comunista y los soviéticos. La llamada de Kennan a modificar la posición de su país en la ONU, se correspondía con ese temor a una hipotética expansión comunista, ya que a su juicio, condenar el régimen de Franco, a parte de contraproducente, no tenía sentido.

En un informe fechado el 26 de julio de 1948, el Departamento de Estado norteamericano insistia en la necesidad de establecer relaciones plenas con España en el campo económico, político y militar. En este último apartado se hace mención a la importancia estratégica de la localización geográfica de España a la hora de prevenir su caída en manos del

24 Foreign Relations United States (FRUS), 1947, Vol. III, 711.52/10-2847, y Anexo, Análisis del Staff de Planificación Politica, para el Secretario y el Subsecretario de Estado, 24-10-1947. págs. 1091 a 1094.

25 FO 371-67871, Z 9953, Embajada en Washington a F.O., 15-11-1947, PRO. 
comunismo, o de un gobierno comunista. Esta es una de las razones fundamentales por las que creían era fundamental asistir a España en la rehabilitación de su economía, pues ayudaría a convertir a España políticamente en un país atractivo para los países occidentales, y a su vez lograría que todos ellos se involucraran en la asistencia a España para reintegrarla en la comunidad internacional. Sólo el pueblo español puede producir los cambios necesarios. La actual situación de corrupción debido a la dictadura, sólo puede ser solucionada si el régimen da pasos hacia la democracia, para lo que Estados Unidos va a intentar convencer a Franco de ello. Sin embargo, el informe también registra está poco grata apreciación: Estamos completamente convencidos de que un régimen completamente democrático y libre es casi desconocido en la historia de España, es imposible de alcanzar en el cercano futuro ${ }^{26}$.

Pero, el 25 de agosto de 1948 tendrá lugar un hecho que ciertamente sorprenderá a propios y extraños. D. Juan y Franco se encuentran en aguas del Cantábrico a bordo del yate Azor. La reunión fue vista por muchos como una burla a los negociadores del pacto, pero mostraba en realidad que el pretendiente al trono contemplaba diversas posibilidades respecto a la forma de llegar a ser Rey de España, y que la de llegar a un acuerdo, convenciendo a Franco de la oportunidad de ser relevado por él mismo, era una de ellas lo cual no disgustaba a muchos monárquicos de! interior que renegaban de las negociaciones con los socialistas. Además, D. Juan podía utilizar ante Franco la baza del entendimiento con los socialistas. Pero también mostraba que Franco estaba inquieto ante la proximidad de un pacto entre monárquicos y socialistas.

Para tranquilizar a sus interlocutores ante la situación creada, el 6 de octubre Gil Robles envia un memorándum al Foreign Office en el que habla sobre las conversaciones entre Franco y $\mathrm{D}$. Juan, y sobre la vigencia de las conversaciones con los socialistas, incluyendo los ocho puntos de acuerdo entre las dos partes ${ }^{27}$. Según dicho memorándum, D. Juan había recibido una nota en la que Franco mostraba su deseo de mantener una entrevista, lo que fue aceptado debido a la situación interna de España, pues podría contribuir a lograr una solución pacífica por todos deseada. También se consideró el deseo de una importante parte de la opinión pública española, deseosa de un acuerdo entre D. Juan y Franco para evitar un golpe revolucionario. En la entrevista, D. Juan se habría ra-

26 FRUS, 1948, Vol. III, Departamento de Estado Política hacia España, 26-7-1948.

27 FO 371-73360, Z 8503 G, Memorándum de Gil Robles para el F. O., 6-10-1948, PRO. 
tificado en los puntos de vista expresados en sus documentos políticos, sin mostrar ninguna disposición a abdicar de sus derechos, y admitió la posibilidad de enviar al Príncipe de Asturias a estudiar a España si tenía lugar algún cambio efectivo respecto a la monarquía. Franco no le dio ninguna indicación concreta del momento de la Restauración, a pesar de afirmar que la monarquia era el futuro de España.

Muchos republicanos, que desconfiaban de las bondades del pacto, a pesar de las garantías dadas por Gil Robles, dieron por muertas las conversaciones. Sin embargo, en el mes de septiembre Prieto declaraba a la agencia United Press: Si Franco pretendió destruir el acuerdo en marcha, ha fracasado por completo en sus propósitos. Tras la entrevista de Franco con D. Juan se ha conseguido llegar a un acuerdo, que ha sido ratificado tras la vuelta de $D$. Juan a Portugal ${ }^{23}$. También Gil Robles se manifestó al respecto, $D$. Juan, pese que no interviene directamente en las negociaciones entre partidos políticos, aprueba las conversaciones iniciadas en Londres en octubre de 1947. Dichas negociaciones con la izquierda anticomunista han alcanzado una satisfactoria conclusión, aunque en orden a evitar que Franco utilice de forma alarmante dicho pacto, éste no ha sido presentado con la apariencia de acuerdo. Algunos partidos pueden verse obligados a desmentir la existencia del pacto, por lo que cualquier desmentido público de los partidos involucrados, no desautoriza el completo acuerdo alcanzado ${ }^{29}$.

La declaración -que ese nombre llevaba como título y no Pacto- que se conoce con el nombre de Pacto de San Juan de Luz, dado a conocer por ambas partes a principios de octubre de 1948, contenía ocho puntos de acuerdo ${ }^{30}$ :

- Promulgación de una amplia amnistia.

- Instauración inmediata de un estatuto jurídico garantizando el ejercicio de los derechos de la persona y estableciendo un sistema de recursos judiciales contra el abuso del poder público.

- Mantenimiento inflexible del orden público y prohibición de las venganzas o represalias inspiradas por motivos religiosos, sociales o políticos.

- Restauración, con el concurso de todos los interesados en la producción, de la economia nacional actualmente amenazada de ruina.

28 FO 371-73359, Z 7742, Memorándum de Prieto al F.O., 17-9-1948, PRO.

29 FO 371-73360, Z 8503 G. Memorándum de Gil Robles para el F.O., 6-10-1948, PRO.

30 FO 371-73359, Z 8130, Documento enviado por el PSOE al embajador británico en Paris, 6-101948, PRO y FO 371-73360, Z 8503 G, Memorandum de Gil Robles para el F.O., 6-10-1948, PRO. 
- Eliminación de la dirección política del país de todo grupo o de toda influencia totalitaria, cualquiera que sea su tendencia.

- Incorporación inmediata de España al grupo de naciones occidentales europeas asociadas en el plan de reconstrucción de Europa elaborado gracias a la ayuda económica de los Estados Unidos y participación de España en el Pacto de los Cinco.

- Garantía del libre ejercicio del culto y de la consideración a la que la religión católica tiene derecho, sin perjuicio debido a las demás creencias de acuerdo con el principio de libertad de pensamiento.

- Después de haber devuelto a la nación, tan rápidamente como las circunstancias lo permitan, las libertades políticas, las fuerzas signatarias de esta declaración se comprometen a consultarla a fin de restablecer un régimen político definitivo, sea por sufragio directo, sea por intermedio de representante, pero, en todos los casos, por medio de un voto secreto al que tendrán derecho de tomar parte todos los españoles de ambos sexos juridicamente capaces. El gobierno que presida esta consulta tendrá que presentar, por su composición y la personalidad de sus miembros, todas las garantías de imparcialidad.

Si hacemos caso al representante británico en Madrid, tradicionalmente bien informado, a finales de 1948 las negociaciones con los socialistas eran para D. Juan secundarias. El encuentro con Franco le había mostrado la fortaleza de la posición de este en España, y que cualquier posibilidad para la restauración de la monarquía pasaba únicamente por sus manos. Además, D. Juan había notado el incremento del interés de los Estados Unidos por los asuntos españoles, y que éste país era ahora más importante para el futuro de España que el Reino Unido. La aceptación por D. Juan de que su hijo se eduque en Madrid, avalaría la creencia de que el Pretendiente había caido en manos de Franco ${ }^{31}$. La diplomacia inglesa estaba convencida de que $D$. Juan estuvo muy influenciado por dos fuentes principales, es conocida la hostilidad de Culberston al pacto de San Juan de Luz, y posible que tanto los americanos como los generales, hayan influido sobre Franco y $D$. Juan con el objeto de lograr llevarlos por el mismo camino ${ }^{32}$.

Mientras tanto, Prieto queria seguir confiando en el proceso. El 28 de octubre de 1948 el PSOE se mostraba crédulo en el pacto descalificando a Albornoz por criticario.

\footnotetext{
FO 371-73359, Z 8361, Embajada en Madrid al F.O., 15-10-1948, PRO

32 FO 371-73360, Z 8827. Embajada en Madrid al F.O., 28-10-1948, PRO.
} 


\section{EL FRACASO DE PRIETO Y EL FINAL DE UNA ÉPOCA}

El Acuerdo existía, era verdad, pero faltaba lo más importante, llevarlo a la práctica, y para ello, el concurso de las potencias democráticas era imprescindible. En julio de 1949, Luis Araquistain, que tan sólo unos meses antes se mostraba entusiasta con el pacto, se sentía ahora decepcionado, cansado de las condenas internacionales que no se traducian en apoyos prácticos, se tiene miedo a derribar a Franco, por miedo de lo que pueda suceder fuera y dentro de España; pero, al mismo tiempo, se tiene miedo también a ayudarle eficazmente. Cree que es hora de renunciar definitivamente a la ayuda exterior, a España sólo la liberarán los españoles, todo lo demás será una pérdida de tiempo y de energía ${ }^{33}$. Y es que, el problema español, que volvió a la Asamblea de la ONU a finales de 1948 y en abril de 1949, no era objeto ya de unanimidades como en 1946, aunque todavia se consiguió evitar la derogación de la resolución de diciembre de ese mismo año. Para los Estados Unidos la discusión del problema español en la ONU será objeto de gran interés, se esforzará en evitar cualquier condena peligrosa para su estrategia y en lograr la derogación de la resolución de 1946 que permitiera la vuelta de embajadores a Madrid, ya que según el Departamento de Estado, ello no implicaría ningún juicio de la política interna del país, dejando a las agencias especializadas de la ONU la decisión de si España debía o no ingresar en ellas ${ }^{34}$.

Era evidente que el panorama internacional habia cambiado, y no en la dirección deseada por los antifranquistas republicanos, de ello nos da idea un informe de la embajada británica en Washington en septiembre de 1949, en el que se recoge que el Departamento de Estado es presionado por el Congreso, que no está interesado en el aspecto ideológico del caso español, ni en la naturaleza dictatorial del régimen de Franco, pues tienen mucho mayor interés en el aspecto estratégico de la cuestión y en el valor que Franco puede tener como aliado en la guerra fría contra el comunismo. Dudan si se puede confiar en que cualquier gobierno que suceda a Franco puede ser tan antiruso ${ }^{35}$.

La guerra fría se había convertido ya, por encima de otras causas, en el principal condicionante de la política mundial. De ahora en adelante, cualquier acontecimiento internacional habrá que verlo a la luz del clima de enfrentamiento entre Estados Unidos y la Unión Soviética. Franco se es-

3:3 Citado por JavieR TuSELl, en Luis Araquistain, op. cit, pág. 92.

34 FRUS, 1949, Vol. IV, Asuntos Europeos, Politica hacia España en la ONU, 2-9-49.

35 FO 371-79698, Z 6027, Embajada británica en Washington a F.O., 5-9-1949, PRO. 
taba encontrando con el salvoconducto que le iba a permitir perpetuarse en el poder. Era difícil que los Estados Unidos apoyaran cualquier cambio en España que pudiera poner en peligro la estabilidad del sur de Europa, y el plebiscito proyectado no aseguraba esa estabilidad, porque además, temían que aun en el caso de que el relevo de Franco se llevase a cabo en paz, la situación fuese aprovechada por los comunistas a corto o medio plazo. El Reino Unido, consciente de que estaba perdiendo la batalla diplomática en beneficio de Estados Unidos, reconocía en octubre de 1949, que debia cambiar la política seguida hasta el momento en vista de la nueva actitud de los Estados Unidos hacia España ${ }^{36}$. Definitivamente, el pacto entre monárquicos y socialistas no iba a pasar del papel.

En los meses previos a la reunión de la Asamblea de las Naciones Unidas que comenzará en septiembre de 1950, el gobierno republicano continuó haciendo esfuerzos en pos de evitar la temida derogación de la resolución de 1946. Asimismo, el monárquico Félix Vejarano, y el socialista Trifón Gómez, acudieron al Foreign Office y a la Embajada norteamericana en Londres, con el fin de dejar un documento firmado por ambos que hacia saber que el acuerdo entre las dos partes seguía en vigor, reafirmando el compromiso de contribuir a los fines del recién constituido Tratado del Atlántico Norte cuando cambie el régimen vigente en España, y recordando las promesas de apoyo hechas por Francia, Estados Unidos y Gran Bretaña al Pacto entre las dos fuerzas ${ }^{37}$.

Pero, el 4 de noviembre de 1950, en plena escalada bélica tras la invasión norcoreana de Corea del Sur en junio, y pese a que no se habian registrado cambios en la situación que motivó la resolución condenatoria contra España en 1946, la Asamblea de la Naciones Unidas autoriza la derogación de la resolución de 15 de diciembre de 1946.

El 3 de noviembre, y antes de marcharse a México, Prieto envió una carta a la comisión ejecutiva del PSOE que contenía su dimisión de los cargos de presidente nominal del partido, y del Comité de Enlace, y donde hacia una implacable autocrítica, que es publicada el día 6 por "El Socialista": Mi fracaso es completo. Soy responsable de haber inducido a nuestro partido a fiarse de poderosos gobiernos democráticos que no merecian esta confianza, como acaban de demostrarlo. Por mi culpa, mi partido ha sido victima de una ilusión que me ha deslumbrado [...] Aunque

\footnotetext{
36 FO 371-79698, Z 7409, Intorme F.O., 12-10-1949, y Policy of H.M.G. towards Spain. 14-11. 1949. PRO.

${ }_{37}$ FO 371-89483, WS 1016/28, Carta de F. Vejarano y Trifón Gómez, e informe F.O., 20-51950 y $2-6-1950$, PRO.
} 
algunos monárquicos hayan debilitado el Acuerdo con vacilaciones absurdas, y declaraciones incongruentes, he juzgado que debiamos mantener este Acuerdo, cuya eficacia se fundaba en la sinceridad y la firmeza de los paises democráticos más que en los talentos de nuestros aliados provisionales. Esta sinceridad y esta firmeza han fallado y me faltan ánimos para una colaboración que tal vez no convenga mantener aunque, no tiene otra finalidad que el plebiscito ${ }^{38}$. El mensaje de Prieto no provocó, sorprendentemente, ningún cambio en la línea seguida por los socialistas, y así en el congreso que el PSOE celebró el 1 de abril de 1951, se aprobó una declaración donde se consideraba a la coalición circunstancial con la Confederación de Fuerzas Monárquicas un instrumento eficaz para facilitar la desaparición de Franco. Pero faltaba un golpe definitivo que al menos aclararía las cosas. El 10 de julio de 1951, D. Juan dirigía una carta a Franco, cuyo texto definitivo, según él, no ha sido dado a conocer previamente a ningún organismo monárquico, y en él que dice tener las manos libres de ataduras y pactos respecto al futuro [...] esto no quiere decir que haya ignorado las actividades de elementos monárquicos que bajo su exclusiva responsabilidad han procurado neutralizar la posible tendencia revolucionaria de sectores obreros anticomunistas, encauzándoles por rumos de cooperación social y patriótica [...] se me ha acusado, creo que maliciosamente, por la propaganda antimonárquica, de no estar identificado con el Movimiento Nacional [...] pongámonos de acuerdo para preparar un régimen estable ${ }^{39}$. EI PSOE pidió inmediatamente aclaraciones a la Confederación de Fuerzas Monárquicas para saber si se identificaba con las palabras del Pretendiente, y se encontró con esta contestación: La restauración monárquica supondrá una transformación del Estado que satisfaga las tendencias modernas de la oposición a Franco ${ }^{40}$. El Pacto quedaba ya como un viejo y curioso documento, mientras la frustración y la rabia se apoderaba del ánimo de todos aquellos que habían creído ver en el acuerdo entre monárquicos y socialistas la salida perfecta para devolver la democracia a España.

En Europa, la política americana respecto a España producía inquietud, sobre todo en el Reino Unido. En julio de 1951 el gobierno británico y francés concertaron un documento que informaba al gobierno estadounidense de su oposición a cualquier intento de asociar a España a la defensa

34 Citado por JOSE M. ${ }^{a}$ DEL VALLE, op. cit., págs. 316 y 317.

39 ARE 1.12.4., 236.1., I PAIETO “El principe mendigante". El Socialista 25-10-51. Tambièn en J. BorRÁs op. cit., pág. 141.

$40 \quad$ Ibid., pág. 142. 
europea ${ }^{41}$. También les preocupaba las consecuencias que el acercamiento americano a España podría tener para sus intereses económicos. $Y$ es que existía una presión creciente por parte de algunos sectores de la economia norteamericana para conseguir ventajas comerciales con España. Un país necesitado de bienes que no podía comprar con su economía en ruinas, a no ser por medio de créditos generosos que sólo podia conceder el mismo país que podia influir para lograr el fin de su aislamiento internacional. Y es que Estados Unidos se enseñoreaba del viejo continente, y España no iba a quedar al margen, aun con las características propias y diferentes que la diferencian del resto de Europa. El gobierno republicano no se engañaba al respecto, su presidente Albornoz que veía desvanecerse las posibilidades de echar a Franco y como los Estados Unidos planeaban la construcción de bases aéreas en territorio español, protestaba de la concepción errónea de que Franco era el anticomunismo y añadia: El gobierno republicano español, sin recursos materiales, abandonado por los que más deberían sostenerlo, es sólo una fuerza moral, pero es, nadie puede dudarlo, una gran fuerza moral ${ }^{42}$. Al exilio español no le quedaba más que esperar que en algún momento, las potencias occidentales, y sobre todo Estados Unidos, consideraran que había llegado el momento de echar a Franco del poder.

Detrás de este amargo reconocimiento, hay, que duda cabe, la frustración de miles de españoles que habian confiado en que las democracias occidentales vencedoras de la guerra mundial ayudaría a terminar con una dictadura incongruente con la Europa democrática. A cambio, se encontraron con una nueva guerra ideológica sin trincheras, al menos en Europa, que les volvía a alejar del ansiado retorno a su país que con justicia deseaban equiparable a la Europa democrática que también ellos habían ayudado a construir.

41 FO 371-96185, WS 1071/69, F.O. a embajada en Washington, 1-7-51, PRO.

42 ARE, 1.13.2., 735.1., Declaraciones de A. de Albornoz, (ca. 1951), FUE. 